Canadian Journal of Action Research

Volume 21, Issue 2, 2021, pages 25-46

\title{
LESSONS LEARNT ON DESIGNING A COMMUNITY-BASED PARTICIPATORY RESEARCH STUDY ON TRAUMA: A QUALITATIVE STUDY WITH ARABIC SPEAKING REFUGEE NEWCOMERS AND THEIR SERVICE PROVIDERS
}

\author{
Mehmoona Moosa-Mitha \\ University of Victoria \\ Bruce Wallace \\ University of Victoria
}

\begin{abstract}
Few studies engage refugee newcomers in the design phase of a research project even when studying issues that are of significance to them. This preliminary study aimed to engage Arabic speaking refugee newcomers living with trauma and their service providers in designing a community-based participatory research (CBPR) approach to the study of trauma within this community. Focus groups with Arabic speaking refugee newcomers and their service providers confirm participants' views of trauma as a significant issue in their lives, affirm CBPR's principles of participation and action-oriented research, and highlight the benefit of research that informs the integration of trauma responses within resettlement processes. Lessons learnt about implementing a CBPR approach to studying trauma include addressing power imbalances in research, the essential role of action within research, and the value of experiential knowledge and engagement.
\end{abstract}

KeY WoRd: Community-based participatory research (CBPR); Education; Healthcare; Refugee; Social services; Trauma

INTRODUCTION

Canada is experiencing a recent large-scale resettlement effort. In 2015, the government's response to the civil war refugees from Syria was a commitment to rapidly accept 25,000 Syrian refugees by 2016 and a subsequent 10,000 after that. In 2017, there were 44,000 resettled refugees in Canada - an unprecedented number of refugees in the country's 
recent history (Office of the Auditor General of Canada, 2017). Globally, Canada was recognized for admitting the largest number of resettled refugees in 2018, and came second in granting citizenship to large numbers of people who had arrived as refugees (United Nations High Commissioner for Refugees [UNHCR], 2019). As global displacement continues, Canada will continue to support global resettlement initiatives and prioritize security for refugees and displaced persons (Immigration, Refugees and Citizenship Canada [IRCC], 2018).

Trauma and violence are clearly associated with the phenomenon of forced migration both in the pre- and post resettlement phases of the lives of refugee newcomers (Beiser \& Hou, 2016; Bruhn et al., 2018). While studies on the presence of trauma in the lives of forced migrants abound, scholarship that centres the experiential voices and perceptions of refugee newcomers is scarce (George, 2010; Osman et al., 2017). Moreover, as researchers who have utilised community-engaged approaches to research in our work for a significant amount of time, the absence of studies that engage refugee newcomers in the design stage of research exploring trauma in their lives was also problematic. Research studies are not neutral in design and execution, and taking our cue from principles of community-based participatory research (CBPR), we wanted to involve members of the refugee newcomers' community in designing of a research project on trauma among refugee newcomers.

\section{AIM OF RESEARCH STUDY}

We developed a preliminary research study with the aim to engage refugee newcomers and their service providers to share their perceptions and insights on the designing of a CBPR study on trauma that was culturally inclusionary. Using focus groups, we asked participants questions on whether a study on trauma would be meaningful to them and why; what a culturally appropriate research design should include; what their research priorities were; and based on their experiences, what aspects of trauma they would consider important to be included in a study on this subject. In this paper, we share important lessons on designing and conducting a CBPR study on trauma that we learnt from analysing the results of participants' narratives and insights.

The present research originated from a year-long study (2015-2016) by Moosa-Mitha with Syrian Muslim refugee women who recently moved to a Canadian city. Using a communitybased participatory approach to research, participants were recruited on a voluntary basis from the local refugee and immigrant resettlement agency. Eligibility criteria for participating in this study included participants who: were refugee newcomers; arrived to Canada under a year from the start of the study; and identified as Syrian Muslim women over the age of twenty-one. The aim of the research was to better understand resettlement trajectories and develop a social action plan to support the participants and their families in their processes of resettlement in Canada. A group of six to nine Syrian Muslim women met with Moosa-Mitha biweekly for a period of six months and discussed different aspects of their resettlement trajectory. Trauma emerged as an enduring phenomenon in the participants' lives based on their experiences of having lived in a war zone as well as exclusionary experiences they had encountered in Canada. The research shifted to action with a counsellor joining the bi-weekly groups and offering therapeutic exercises the 
women participated in to address trauma. The women began to question the limits of this intervention, wondering if their husbands and sons would ever participate in such participatory action research studies and whether they would be 'culturally suitable'. As a result, the researchers concluded that a research study on trauma should be developed in ways that centred the voices of the participants in the designing of the study prior to implementing a CBPR study on exploring trauma in the lives of refugee newcomers.

\section{COMmunity-BASEd Participatory ACTION ReSEaRch}

Community-based participatory research (CBPR) is an approach that engages community equitably in all phases of the research process for the purpose of producing knowledge and taking action for positive change (Israel et al., 2001; Wallerstein \& Duran, 2006). The research process explicitly identifies and addresses issues of power within the research collaboration processes (Israel et al., 2005; Wallerstein \& Duran, 2010). As an emancipatory approach to research, CBPR is dedicated to working with communities facing marginalization and structural oppressions in addressing issues such as gender discrimination, racism, and classism (Minkler \& Wallerstein, 2008). Participation in CBPR is much more than engaging a community as a site for research as it includes authentic collaboration that implies a long-term commitment by researchers to sustain relations with community and ensure that sustainability is feasible far beyond data collection or the production of a report (Israel et al., 1998). In CBPR the research is not an end in itself, but rather a means for engaging researchers to participate in the larger context of the community and social change over the long term (Wallace et al., 2015).

The researchers for this project both have long-standing roles in communities and active commitments to social justice work and movements. As a racialized newcomer cis-woman who is invested in decolonial research methodologies, Moosa-Mitha brings many years of experience in CBPR on issues of citizenship and migration, working closely with Syrian and Muslim communities within an anti-racism and transnational feminist framework. Wallace identifies as a White, settler, cis-man community activist and scholar and has experienced with CBPR within a local context with a focus on mental health and substance use, working from a social justice and harm reduction framework.

While CBPR is considered an emancipatory approach to research that is rooted in social justice, the approach has inherent challenges and risks that require attention. When engaging and developing relationships with community members who may be experiencing life circumstances and structural vulnerabilities that make participation difficult or risky, such as lived experiences of trauma, it is vital that these challenges not be glossed over but fully addressed (Mayan \& Daum, 2016). CBPR is intended as an ethical practice but it is not inherently ethical and researchers recognize that the research process can inadvertently put people at risk (Wilson et al., 2018), including refugee newcomer groups (Brabeck et al., 2015). For example, we were concerned that a study of trauma could result in re-traumatising research participants. Wilson and colleagues' (2018) scoping review explores these ethical challenges and recommends that researchers are informed about the unique connections between the methods of CBPR and the ethical issues that they generate. 


\section{Methods}

A research team was developed that included the two university researchers (Moosa-Mitha and Wallace) and two community agency representatives, one from the local resettlement services centre for immigrants and refugees and one from an immigrant and refugee counselling service. This team developed the qualitative research design and collaborated throughout the research processes. Through several meetings and emails, the team collaboratively defined the parameters for research participants, recruitment strategies and locations for focus groups, the questions that formed the interview guide, strategies regarding compensation, supports and translation, roles in the research processes and more. An ethics application was developed, submitted and approved by the University of Victoria Human Research Ethics Office (18-1158).

\section{Participants}

For the purposes of the study we used a loose and broad definition of trauma that was sociological in nature. In this study, an immigrant or refugee experiencing trauma is someone living with emotional shock as a result of one or a series of stressful events in their lives pre-, during, and post immigration. The study included forty-six participants from two groups. The primary group comprised participants who self-identified as living with trauma. This group consisted of refugee newcomers (with and without status) who had lived in Canada for at least two months and were 14 years of age or older. The second group consisted of settlement workers and counsellors working with refugee newcomers who experience trauma.

The community partners facilitated participant recruitment within their agencies through a random and a purposive sample in two ways. (1) They put up posters at both agencies that described the research aims, eligibility, and ethical details. Refugee newcomers were invited to volunteer to participate in the research project if they either self-identified as living with trauma, or worked with refugee newcomer populations living with trauma. (2) They approached participants they were working with who were living with trauma to see if they were interested in participating in the project.

Care was taken to assure participants that choosing not to volunteer or participate in the project would have no bearing on their relationships with agency staff. In the end, all refugee newcomers who expressed interest in participating in the project were from the immigrant and refugee resettlement centre, probably because of the relationship they had with that agency community partner. All newcomer refugee participants were Arabic speakers with Middle-Eastern origins. Contrastingly, the service provider participants ended up being recruited mainly from the refugee newcomer counselling agency and were representative of predominantly white, women trauma counsellors with only one settlement worker (non-white) from the resettlement agency participating in the focus group.

Four focus groups were held in the community agency sites over a few weeks in 2019. These included a group for woman refugees who experienced trauma $(n=12)$, a group for 
men refugees who experienced trauma $(n=12)$, a group of teenage refugees who experienced trauma $(n=10)$ and a group for service providers $(n=12)$.

\section{Data Collection}

The group for women was facilitated by Moosa-Mitha, and the group for men by Wallace and a research assistant who was a man of colour to ensure greater comfort with the research process. The group for teenagers was facilitated by a younger graduate research assistant with previous experience working within refugee camps, and the service provider group was facilitated by one of the service provider collaborators on the research team. All participants were provided a stipend of \$25 (CAD). A trusted translator was engaged for the focus groups. The translator was a settlement worker with deep connections to the community. Consent forms were used and all groups were audio recorded with recordings transcribed, including translation from Arabic to English for the two adult groups (the teenage group used only English).

The facilitators used the semi-structured interview questionnaire developed by the research team. The discussions focused on asking participants the following questions with additional probes: "Do you consider undertaking research on trauma to be a worthwhile project? And if so, why?"; "What are the things we should keep in mind when we design the study to ensure that the study is culturally acceptable?"; "What are the characteristics that you would look for in a good researcher?"; "What do you think are important areas that should be included in a study on trauma?" Two hours were dedicated to each group and following each group, a meal was shared among the participants and facilitators.

\section{Analysis}

Interviews were transcribed verbatim, translated from Arabic to English for those focus groups where Arabic was the medium of discussion, and field notes from all facilitators were compiled into one narrative. Transcripts were analyzed using primarily thematic analysis (Braun \& Clarke, 2006). Moosa-Mitha led the analysis process, and reflexivity was ensured through regular reflective discussions between both Moosa-Mitha and Wallace. Following the six phases of thematic analysis outlined by Braun and Clarke (2006), we (a) familiarized ourselves with the data (b) generated initial codes; (c) searched for themes; (d) reviewed themes; (e) defined and named themes; and (f) synthesized the findings.

\section{FINDINGS}

Four main themes pertaining to designing a CBPR study on trauma among refugee newcomers emerged: 1) the importance of conducting research on refugee newcomer trauma was confirmed; 2) cultural safety in research with refugees who experience trauma was defined; 3) the roles of researchers in engaged research to study trauma were described; and 4) trauma was defined by participants.

\section{Theme 1: Confirmed Importance of Conducting Research on Trauma}

CBPR methodology stresses the importance of initiating research on issues raised by a community within a specific geographical location that is of significant concern to them (Israel et al., 2001; Wallerstein \& Duran, 2006). As stated earlier, the identification of 
trauma as a significant social issue emerged from an earlier study with Syrian Muslim refugee newcomers. However, it was important for the research team to determine if participants from the broader newcomer refugee community also viewed trauma as a significant issue in their lives that was worth studying.

Refugee newcomers who participated in the current study affirmed the importance of conducting such a study, citing three reasons: (a) by narrating stories that spoke to the high level of trauma in their lives; (b) by talking about the benefits they envisaged in participating in a collective exploration of trauma and its effects; and (c) by envisioning that such a study would help in identifying social services that they could access. The following is a quote from a woman participant describing the level of trauma in her life:

Some days I get crazy. There was a day when I was feeling suffocated and just left the house. My husband and son were looking for me. I kept walking and walking for two hours with no destination. I talk to myself. My husband is sick and my son is not working, we have no income so I just kept walking. My daughters (in Syria) call and cry to me; they miss me, my extended family in Syria call and complain about the bad living situation there. So there are lots of things on my mind, I feel like my head will explode.

Numerous participants shared stories such as the one above, listing various issues in their lives that they loosely defined as traumatic.

Participants also spoke of the benefits of participating in a community-based research process devoted to better understanding trauma. As one man suggested, "Yes if we talk about it we will feel good." A woman participant also agreed stating, "We feel better to let it out. Each one of us has a pain in her heart that she is suffering from." Across all three focus groups with refugee newcomers, there was consensus that by sharing their experiences of trauma they were building community and lessening the pain of trauma that was felt more keenly when experiencing it in isolation.

A third reason that participants gave for why they considered a research study on trauma to be essential was the possibility it offered participants to identify community support services to address trauma. One participant said,

There is no one here who can listen. For example, if we tell our friend - she might not be able to help. We also can't help because we don't know where we can go to find relief, how do we solve our problems.

A male participant affirmed this by stating, "If something is bothering me, I don't know where to go to make a complaint and explain my concerns." The service provider group also made a similar connection, stating that researching trauma was important to assess support services refugee newcomers were currently receiving: "Studying trauma is important in order to evaluate the services that they (refugee newcomers) have received whether we helped them, why not, how we could do better." Another service worker asked, 
"What do the refugee population think is most helpful to them?" One service provider further suggested research "to see how the resettlement process is maybe fostering this trauma or maybe how can we prevent trauma in services which are trauma informed and culturally appropriate."

Overall, participants offered multiple reasons for why they thought a study on trauma amongst refugee newcomers was important. Refugee newcomer participants emphasized the importance of sharing the significant levels of trauma they were experiencing in their lives and identifying suitable services as rationale for further study of trauma. At the same time, service providers spoke of the importance of evaluating present services and their effects on refugee newcomers. As a research team, we felt we had a clear mandate from the participants to undertake a study on trauma that also included an exploration of interventions that were culturally suitable (as defined in the next theme).

\section{Theme 2: Culturally Suitable Research with Refugees}

The researchers wanted to know how participants would define culturally-suitable or nonWestern-centric research practices that would facilitate research on a sensitive subject like trauma. We heard plenty of feedback from youth participants who used their experiences relating to other Canadians as well as social workers and therapists to share what they felt constituted inclusionary and respectful research practice. Youth participants were insistent on researchers' responsibility to be knowledgeable of their cultures. One youth resisted having the role of an educator imposed on him:

Everything I am saying is educatable, you must study about it. There are books, or you can put on YouTube videos and just learn more and more...when they ask me what's Kurdish, I think what I should explain. There are books, they can go and read it. I can't explain everything to them.

Relatedly, understanding culture in all its diversity and in non-essentializing ways was also identified as important within an inclusionary research framework:

I am from Syria but I am not the same as other people. Every country has different people from different cultures or different lifestyle, or different thinking. When I came to Canada, most of them were telling me and behaving with me the same way how they were behaving with them (gesturing to other women in group). For example, they were shocked why I don't put the hijab...like I am Kurdish, and they have no idea what is Kurdish. I am like 'what?!' In my opinion, I think it is very disappointing for a newcomer. When we came here, they don't know what is Kurdish or what is Christian. When I told them there were Christians in Syria they were like really! They were shocked like it is something very strange... Yeah it is a country. It has many people, so it has different religions, cultures, lifestyle. They should not be the same.

Social difference was viewed as natural and normal and youth participants expressed their disappointment at practitioners/researchers lack of cultural awareness. Critical social 
theorists reflect a similar understanding of social identity constructions, emphasizing the importance of centering social diversity in research practice and acknowledging the fluidity and multiplicity of social identities (Moosa-Mitha, 2015).

Other youth spoke against research biases that were labelled as gendered and Islamophobic. One young woman spoke about the gendered nature of discrimination they had experienced in Canada where women wearing hijabs (head scarf) were judged more stringently in terms of their everyday behaviour and were expected to be "perfect." They also provided instances of experiencing Islamophobia in their encounters. Youth participants were very keen to ensure that Islamophobic practices were not perpetuated by researchers, a young woman stated: "It's not because of my religion that I am doing bad things. I don't expect that you do something because of one's religion. Regardless of everything, I am a human being."

The gendered nature of Islamophobia has been studied extensively in western societies (e.g., Allison, 2013; Jiwani, 2011) as has anti-Muslim sentiment in society which is on the rise globally (Poynting, 2015). It is therefore not surprising that participants were keen to ensure that such behaviour was not repeated by researchers conducting a study on trauma with marginalised communities, particularly those from the Middle-East.

Another youth participant spoke about the racism that he had experienced in Canada as an example of what researchers should be careful not to repeat: "They say in North America, people are more open-minded and there is no racism, no judgement, people are very kind and nice. But we can't say all Canadians are like that...Not all of them are open-minded."

It was not the research method that participants recommended changing in order for the research to be culturally suitable. Rather, participants pointed to cultural prejudices and ignorance about the diversity of culture as making the research process exclusionary. The research team wanted to ascertain whether refugee newcomer participants perceived researchers who did not share the same cultural background as facing an unbridgeable cultural gap, making it impossible for them to facilitate the research. The findings suggest that participants not only felt that researchers representing dominant cultures would be capable of undertaking this research, but also felt that it was their responsibility to do so by making themselves knowledgeable about the cultures of the participants. The research team also found it interesting that participants defined cultural suitability first by defining what it was not through examples of discriminatory practices that they had experienced, and then in positive terms by defining culture in non-essentialist ways and emphasising differences and diversities of cultural expressions. In the discussion section of the paper, we further analyze the definition of cultural suitability suggested by participants' narratives.

\section{Theme 3: Role of Research in a CBPR Approach to Studying Trauma}

This preliminary research study vividly exposed the ethical dilemmas and risks of research with refugee newcomers experiencing trauma, particularly when using CBPR, which seeks to center participant voices within the research processes. Within this theme, we identified 
three sub-themes in the data that illustrate the ethical dilemmas and risks present when studying trauma in refugee newcomer groups. The first sub-theme concerns the risk of the research process itself causing further trauma or re-traumatising participants. The second sub-theme relates to the risk of treating participants as victims rather than as survivors who are agentic. A third theme is the ethical and practical imperative of research to be action oriented.

The possibility of triggering trauma through the research process and the implication that the researchers must pay attention to this risk was voiced by a service provider who cautioned: "Is there a need for a research study like this? Absolutely. They just have to be careful about how it is done carefully." The participants identified specific skill sets that they felt were important for research facilitators to have in order to mitigate against the risk of retraumatizing participants. For example, a youth stated that researchers should "possess mental health counselling skills." The participant continued, "I would prefer to have a conversation with a professional person because I know they will be able to manage my feelings a little bit and make it safer." There was consensus among all participant groups that research facilitators should be equipped with the appropriate training to gain counselling skills before conducting the study.

Participants emphasized the importance of researchers treating participants as agentic and resilient and not as victims, as one young woman stated:

When I sit with them (counsellors), I try to avoid talking about my home or culture and at the same time I don't like them to look at me like they feel sorry for me or feel sad then I look weak and I don't want that in my personality.

A service provider similarly cautioned against the treatment of research participants as victims:

Not to treat clients (participants) as though they are enfeebled...(this) notion of one nation under therapy... and through a lot of this trauma stuff we are actually developing what they call national enfeeblement. So... taking some of the bravest people among us, who have been through stuff that we cannot even imagine - they are on their feet, they are functioning, and then approaching them like they are really screwed up as opposed to enabling a natural environment where they would naturally feel safe to speak.

Another service provider suggested that treating refugee newcomers living with trauma as agentic within the research process meant that the researcher needed to take a learner role and ask their participants advice: "How can we ask questions, how can we learn about your experiences within trauma... in a very humble position of learning we want to learn how to do that without re-victimizing or triggering this kind of emotional response."

Participants evoked an ethical dilemma for us during the preliminary research process when they insisted that this research was worth doing to the extent that it brought about 
positive social action. We had anticipated that this would happen in the study we were designing, not in this preliminary one. One woman asked, "Will this research help us? Can you help me get a better house? My family cannot live in this condition." Another expressed the futility of talking to researchers when she was told it was the government that was in charge of settlement processes. She questioned, "When we ask for guidance, service provider tells us it's the government, the government, if there are no solutions, then why did you bring us here?" Meanwhile, another woman in this group expressed her exasperation: "...they feel bad and tell me sorry, sorry and pat me on my shoulder. I am tired of this ... help me please, don't just say you are sorry.” Another woman participant expressed the need for not just researchers to listen but also for government to listen, stating, "We beg the professor (researcher) to bring us a representative from the government."

The importance of researchers to impact social outcomes was reiterated in the men's group as well, as one man asked "...the talk that is being recorded, will they be able to get us solutions to our problems and stresses?" A service provider further defined the research purpose as, "research should help the people not the other way around, to help researchers get post docs."

Another woman participant reinforced the urgency of taking social action and took an activist tone:

Just let her (researcher) tell us which office is between us and the government, so we can go and talk to them. I would go to all the Syrian families and make a list of all the things we need help with.

Another woman added "We are moms. If we want to go and do a protest, we will. We just want to go to an office and ask them to help us bring our children to Canada."

The urgent action required to address the participants' needs made it clear that the primary role of research should be to aim for social change. While participants' emphasis on action-oriented research affirmed our chosen research methodology, it also created an ethical dilemma. This was a preliminary study with the main objective of designing a study that centred the voices of participants in the execution of a CBPR study on trauma. As such, we were not prepared for the kinds of immediate actions participants asked of us. Fortunately, settlement workers and counsellors were partners on this project and present at most of the focus groups and as they knew the participants well, they integrated the needs that participants expressed in their work with them.

The lessons learnt from the analysis of this theme will inform the design of the next study in ensuring that researchers have requisite anti-oppressive and counselling skills, pay attention to language to ensure that the questions themselves do not assume a saviour type discourse which treats refugee newcomers as victims, and take a 'humble' stance in learning from the participants when articulating questions. Most importantly the analysis 
shows that CBPR action-oriented research aligns with participants' own views of research methodology.

\section{Theme 4: Defining Trauma}

We had deliberately used a broad definition of trauma as we wanted to garner a beginning understanding of how participants would define trauma in the focus group discussions, which would inform our future research on trauma amongst refugee newcomers. All participants talked at length about the nature of trauma that they had experienced and, in so doing, identified important aspects of trauma that will be integrated in our study.

Many participants described trauma in relation to the conditions that triggered forced migration in the first place. One man described it as follows:

When I was living in Syria, it was like hell. When I came to Canada, I found it was a beautiful city. Thank God I am happy here. As soon as I arrived in Canada, I immediately felt like a human being.

This view was balanced by participants who spoke about trauma as on-going and current. One woman spoke movingly about how trauma was not just a singular event in time, but rather had a multiplier effect as a result of forced migration. In the following excerpt, she talks about the impact the news of her mother's death had on her while she was in transit living in Egypt after having fled Syria:

I experienced trauma in Egypt. My mother was sick when we left Syria but it wasn't serious - she was 62 years old. During that time, my daughter who lived near me in Egypt having fled Syria, called me and asked me to come over to her house... My daughter's voice sounded very weird.... From the tone of my daughter's voice, I felt anxious and worried ... Subhanallah (Glory be to God) how the heart feels when something isn't right ... I asked, 'My dad died?' My daughter replied, 'no mom it's your mother that passed away.' The moment I heard that it was my mom, I fell and couldn't feel anything. They rushed me to the ICU and discovered that I had a minor stroke in my brain... I wasn't expecting my mom to die... It was like the whole world stopped. The trauma still hurts me now. I sometimes feel like I can't breathe... It's been 5 years since I haven't seen them. I tell myself I wish I died and didn't leave Egypt and Syria.

Because of the multi-directional flow of migration trajectories, we cannot assume that refugee newcomers will move directly from one country to the country of resettlement (Stasilius, 2008). Trauma itself is experienced as a continuum of the entire migratory event and cannot easily be parcelled into segments of pre- and post-migration.

Participants also recounted experiences of trauma as a result of resettlement in Canada. Participants frequently enacted the role of 'grateful' refugee as they described ongoing traumatic experiences during their resettlement processes and the need to present as 'okay': 
They brought me here to Canada and I am thankful to them for helping us, but they also threw us from cold-pleasant honeymoon to the hot struggling hell. We saw life and death during the war. But we did not see this kind of trauma. In Syria we used to run and go to my sister's house, or this person gives me a hug. But here my sister is barely able to handle her house or take care of her husband. Now we laugh at the newcomers. They are happy to come to Canada and we understand but they don't know what is coming ahead. Open my heart, half of it is burning from pain and another half is happy. People ask me if I am happy, I say I am okay.

It is significant that when describing her experience of trauma, the participant above describes the warring conditions of Syria from which she escaped as being favorable to the trauma she experiences in Canada because of the severity of stress from loss of income as well as social relationships. Her narrative also points to the complexity and contradictory nature of trauma and to the fact that trauma is not a universal and monolithic phenomenon where the person experiencing trauma feels only pain or dejection (Koch \& Weidinger-von der Recke, 2009). Rather, as she eloquently puts it, feelings of trauma are contradictory in nature: there is gratitude for having come to Canada and escaping a war zone but there is also pain at the fact that life in Canada is very difficult and social relations are less rich than those experienced in Syria.

Participants identified some of the structural reasons for ongoing trauma during their resettlement processes in Canada, one of which was the limited one-year period of support from the time of arrival in Canada, after which refugees are no longer eligible for government aid. A woman explained, "(Canada) gives money for one year only "honeymoon" from the government. After this year, we get the pressure of expensive housing. We had troubles in Egypt/ Syria/ Lebanon but here our troubles are bigger."

Another woman participant provided her example on on-going trauma in Canada as follows:

My son started working for 1.5 years with a chef doing all the tasks on minimum wage of $\$ 13$. He used to come home dead with pain in his legs. He requested his boss to increase his wage, but the chef boss refused and said you either work or leave. My son just quit the job. Now he is emotionally depressed and tired. He doesn't leave his room. Then he worked at the construction for two months and got fired because he can't speak English. Again, he got more depressed. Then he got another job but got fired again because of English language. He also can't study English because he can't focus. So, everything is tied up and based on the English language. He has been at home for 1 year now and we are financially struggling. He asks me why did you take us out of Egypt? To struggle here? I didn't get married and my education and future are gone. I tell my son to go out with his friends to downtown, he tells me: mom I don't have a penny. How do I go out as a man with my friends and treat myself? 
Studies have shown that one year is not sufficient for successful social integration, particularly in the case of families who are already traumatised and do not have the requisite language skills (Tanasescu \& Smart, 2011; Waters, 2011). Moreover, access to social services is status dependent. People in the process of claiming asylum who have not obtained refugee or permanent residency status are excluded from being eligible for these services, resulting in more acute experiences of trauma:

I came to Canada as a refugee, but I don't have permanent residency or refugee status as yet. So, the government doesn't recognise me. I can't apply to anything from the government. I am used to working and earning. After I reached here, within five months I started having problems I never thought of before. I left all my problems back home on the basis of starting a new life, but now I have serious problems here.

Another structural indicator that causes significant trauma, at least in the lives of newcomers from the Middle-East, are government policies that only recognise the nuclear family as a family unit. Thus, children over the age of 21 or who are married and live away from their parents are excluded from obtaining refugee status obtained by the parents and their siblings who may be younger than them. Many of the participants reported, both in this study and in the afore-mentioned study by Moosa-Mitha (2015), that they had feelings of guilt as well as trauma at being separated from their extended families upon obtaining Canadian permanent residency:

After I came here, I asked them if they can also bring my son who is in Germany. We filled lots of applications and did lots of paperwork. He did DNA testing (1600 Lira- my son had to travel to the capital city to do it. My son and I spent extra money for him to do the test), and an interview and every month I receive an email that gives me hope. After a year and five months, I get an email simply saying my son will not come to Canada. Why do they give me hope all this while with monthly emails? This is a big trauma.

Another woman spoke eloquently to this issue:

We are coming out from war. I am sad and depressed. My spirit/ hopes are getting destroyed. It's been 3 years I haven't seen my children and grandchildren. We are also not allowed to go visit them and they can't come to Canada. As time passes by, my emotional wellbeing is worsening. But living in Victoria is good. The city is beautiful. The community is welcoming, kind and warm. My only trauma is not seeing my children and grandchildren. That's it.

Family separation has been reported by other studies and the media as being the cause of great anxiety and trauma (Miller et al., 2018; Perkins, 2018). Canadian immigration policy reflects a more Western-centric notion of family and does not prioritize reunification of extended family members. 
In summary, experiences of trauma were multi-faceted and complex. Some people's experiences of trauma had historical antecedents, while for others, one set of factors that triggered trauma were compounded by consequences of forced migration and living transient lives. There was clear evidence of on-going trauma for families who struggled with making ends meet a year after arrival, dealing with social relationships that were more individualist oriented, and handling the trauma that resulted from having been separated from extended family members with whom they had close kinship ties.

\section{DisCUSSION}

This preliminary study provided the research team with several important insights that will guide the implementation of our proposed CBPR research study on trauma amongst refugee newcomers settling in Canada. We discuss the significance of these insights in this section with attention to their implications for a CBPR approach to conducting research. This study broadly affirmed the congruency between participants' expectations on how to undertake this research and the principles that guide CBPR approach to research. CBPR offers the possibility for a transformational approach to research that has the potential to develop, implement, and disseminate effective interventions across diverse communities through strategies to redress power imbalances, facilitate mutual benefit among community and academic partners, and incorporate community knowledge into research (Tapp et al., 2013; Wilson, 2018). In this section, we identify three core principles of conducting CBPR as a basis for our next study: redressing power imbalances; identifying mutual benefits of research; and incorporating community knowledge into the study design.

\section{Redressing Power Relations}

An overriding power imbalance identified by participants is the prioritization of academic research interests over those of participants with lived experience wanting social actionoriented research. In our ongoing project, we seek to address this power imbalance in two ways: (1) By ensuring participants' priorities and desires for conducting research on trauma are integrated into the design of the study based on the findings of this preliminary study. Thus, the aim of the study we are planning will not be limited to understanding trauma among refugee newcomer communities, but will also be interventionist and include exploring culturally suitable interventions to address trauma. (2) By engaging participants in this preliminary research process to confirm that trauma was indeed a significant issue, and to identify what kind of research approaches participants value and how participants define trauma. By integrating participants' knowledge about what is essential in research on trauma into our study design, we aim to ensure participants' priorities and knowledge are guiding the study. We will align our research objectives on the basis of these priorities. We are therefore confident about moving on with developing a research study for refugee newcomers living with trauma in a way that reflects community interests and priorities.

Participants in this project identified how stereotyping and racism can enact power imbalances within engaged research. Examples of racist, gendered, and Islamophobic practices were shared as examples by which researchers/counsellors enact power in their 
encounters with refugee newcomers. We will ensure that researchers engaged in this study are equipped with anti-oppressive (AOP) skills training. The training will be guided by Moosa-Mitha's critical theories of citizenship as well as structural theories of trauma and violence, thereby enacting AOP principles by incorporating both structural or system level factors (colonization, racism, etc.) as well as individual or interpersonal level forms of trauma and violence. Anti-oppressive practice attends to the power dynamics present in social interactions and relationships (Al-Roubaiy et al., 2013; Morgaine \& Capous-Desyllas, 2015). Principles of anti-oppressive practices include being aware of essentializing social identities and being self-reflexive when engaging in gendered, racist, or Islamophobic practices, as well as taking an open-minded, humble stance as practitioners (Baines, 2011). Notably, the definition of culture that emerges from the narratives of the participants is political rather than anthropological. Rather than defining culture as a set of ritual practices and ceremonies, participants took a more political view of culture by embedding it within social relations of power inequality. Our proposed study on trauma and culturally suitable interventions will align with this socio-political definition of culture.

Another power dynamic that the participants identified and resisted was the treatment of refugee newcomers living with trauma as victims rather than as agentic and resilient. Researchers' ability to treat participants as agents, as active, and as owning valuable knowledge garnered from their experiences of trauma as congruent with the principles of CBPR (Gouin et al., 2011; Tapp et al., 2013; Wilson, 2018). An important principle of CBPR is to recognize the knowledge, agency, and power of experiential participants (Galea et al., 2019). In our proposed study, we will ensure that research questions themselves do not perpetuate a savior/helper discourse that treats participants as victims.

Another power dynamic identified was in the definition of trauma that emerged from participants' narratives. Trauma is normatively understood as something that is experienced only 'out there' in the country of origin, while host countries are viewed as entirely untouched by conflict (Lester, 2013). However, participants talked about pre- and post- migration trauma in a way that was both personal and structural, and they resisted dominant and orientalist understandings of trauma as associated only with developing countries contrasted to more developed countries, which are viewed as 'civilised' and outside the ambit of conflict and violence associated with forced migration (Lester, 2013). As Browne and colleagues (2015) assert, trauma is both personal and structural and is associated with violence and acts of violation that do not cease just because a person has moved away from a war zone. People from marginalised populations continue to face other forms of violence, often structural in nature, that result in on-going experiences of trauma. Our study we will therefore pay attention to the ongoing nature of trauma, its complex character as well as both the personal and structural factors that interact in experiences of trauma.

From this preliminary study, participant responses related to power dynamics within the research process nuance understandings of how power is understood in CBPR scholarship. For example, we realised that it is not sufficient to include participant voices when designing a study as a process that was separate from the actual study itself. This is 
because participants in this preliminary study wanted to see social action occur at this stage of the study and not at a future time. This reaction from the participants surprised us as we had conceptualised a more linear process with participant input and implementation of the study comprising of two distinct neatly packaged processes. This is an important lesson for us; should we replicate such a study, we would ensure that social action is a part of the research process from the very beginning point of the study. Despite our years as community activists undertaking CBPR, we were also surprised by the incisive challenge to uphold anti-racist practices that the participants offered. We had assumed that the participants would understand culture in anthropological terms and ask for interventions that included practitioners from Middle Eastern backgrounds as cultural informants. In fact, the participants' understanding of power dynamics and their potential for a helping relationship eschewed simplistic definitions of culture. Participants asked for practitioners with greater social justice acumen who could respectfully and humbly incorporate appropriate cultural cues from the participants themselves, so long as they attended to issues of relational equity.

\section{Identifying Mutual Benefits of Research}

Participants were very clear about the benefits that they wanted to see accrue from research studies on trauma. In this study, participants challenged the theory/practice or knowledge/intervention binaries that exists in normative approaches to research. As mentioned previously, participants saw the role of researchers as social change agents whose research should benefit the community as well as academic knowledge development. These views were heartening to note as they are congruent with actionoriented research approaches, including CBPR, which emphasize the importance of research as a tool for transformational social change. CBPR theorizes the role of researchers as facilitators of social change (Minkler et al., 2008). In our ongoing study, we will continue to challenge the knowledge/intervention binary by aiming to develop knowledge on trauma and violence through explorations of culturally suitable and inclusionary practices when responding to trauma.

Moreover, as Gray et al. (2010) note, CBPR bolsters participant empowerment in marginalised communities by paying attention to knowledge development (research) activities as an important aspect of intervention and not entirely distinct from it. In our research, this was reflected in the narratives of the participants who spoke to the value of undertaking research within a community-based, collectivist environment that resulted in positive feelings of empowerment as a result of engaging in the research process. As we continue this research, we will consider creative ways by which the research process is experienced in this collective and empowering manner.

Literature on CBPR often cautions against unintentionally exploiting research participants' good will by burdening them through requests for research collaboration. In our study, we found that participants felt empowered to engage as partners in our research and saw it as a benefit. We had not anticipated such a strong positive response and hope that more can be written on the benefits of research collaboration for participants through CBPR. 


\section{Incorporating Community Knowledge into the Study Design}

In CBPR, community knowledge is incorporated into research to identify and address social inequities and disparities in accessing health/social care (Galea et al., 2019). In our study, participants identified several inequities that we will study in more depth in our proposed study. Lack of familiarity of available health and social services was consistently cited as a significant barrier to accessing suitable services. This systemic issue included a lack of available translation services and barriers in locating information on where refugee newcomers could go to voice concerns about the impact of exclusionary social policies/practices.

A source of inequity identified by participants in this study was the lack of acknowledgement by professionals of the degree to which trauma acts as a significant barrier to the efficacious resettlement of refugee newcomers. While Moosa-Mitha's earlier study (2015) provided brief insights into the co-relationship between trauma and resettlement issues in Canada, the present study identified more clearly the systemic and structural nature of social inequities that were experienced as traumatic, and which negatively affected resettlement efforts. Participant narratives spoke clearly of the failing of government programs that inflicted severe stress (trauma) on refugee newcomers as they struggled to get on their feet and live independently of government support within one year of arriving in Canada. While studies have critiqued the narrowness and inadequacy of state support in facilitating resettlement processes of refugee newcomers (Hyndman, 2011; Palmary, 2018), very few have specifically analyzed trauma and its relationship to the resettlement trajectories of refugee newcomers (Simich et al., 2005; Simich \& Andermann, 2014).

This is an important finding of this preliminary study, and in the ongoing study, the relationship between trauma and resettlement will remain a key area of focus. The aim of our proposed research will therefore be to connect understandings of trauma and violence on the resettlement trajectories of refugee newcomers and culturally suitable responses to trauma within a multi-disciplinary perspective.

\section{Conclusions}

The aim of this preliminary research study was to engage Arabic speaking refugee newcomers living with trauma and their service providers in designing a CBPR approach to the study of trauma within this community. Community based participatory research (CBPR) offers the possibility for a transformational approach to research that has the potential for action through engagement strategies to redress power imbalances, facilitate mutual benefit among community and academic partners, and incorporate community knowledge into research. This paper provides insights to inform research and researchers seeking to engage refugee newcomers who experience(d) trauma - whether in the past or ongoing - in ways that are grounded in principles of cultural safety, trauma and violence informed care and CBPR values. While trauma and violence are clearly associated with forced migration, not enough is known about the experiences and understandings of individuals with trauma, culturally suitable interventions, and the effects of trauma on their 
resettlement processes. Future research studies on culturally suitable responses to trauma should also incorporate resettlement trajectories as an aspect of that inquiry.

\section{REFERENCES}

Allison, K. (2013). American Occidentalism and the agential Muslim woman. Review of International Studies, 39(3), 665-684. https://doi.org/10.1017/S02602105120 00289

Al-Roubaiy, N. S., Owen-Pugh, V., \& Wheeler, S. (2013). The experience of exile-related stress among Iraqi refugee men in Sweden and its implications for counselling and psychotherapy: A qualitative study. Counselling Psychology Review, 28(2), 53-67.

Baines, D. (2011). An overview of anti-oppressive practice: Roots, theory, tensions. In D. Baines (Ed.), Doing anti-oppressive practice: Social justice social work (pp. 1-10). Fernwood Publishing.

Beiser, M., \& Hou, F. (2016). Mental health effects of premigration trauma and postmigration discrimination on refugee youth in Canada. Journal of Nervous and Mental Disease, 204(6), 464-470. https://doi.org/10.1097/NMD.000000 0000000516

Brabeck, K., Kene, P., Lykes, M. B., \& Sibley, E. (2015). Ethical ambiguities in participatory action research with unauthorized migrants. Ethics \& Behavior, 25(1), 21-36. https://doi.org/10.1080/10508422.2014.920707

Braun, V., \& Clarke, V. (2006). Using thematic analysis in psychology. Qualitative Research in Psychology, 3(2), 77-101. https://doi.org/10.1191/1478088706qp063oa

Browne, A. J., Ford-Gilboe, M., Varcoe, C., \& Wathen, C. N., \& EQUIP Research Team (2015). EQUIP healthcare: An overview of a multi-component intervention to enhance equity-oriented care in primary health care settings. International Journal for Equity in Health, 14(1), 152-162. https://doi.org/10.1186/s12939-015-0271-y

Bruhn, M., Rees, S., Mohsin, M., Silove, D., \& Carlsson, J. (2018). The range and impact of postmigration stressors during treatment of trauma-affected refugees. Journal of Nervous and Mental Disease, 206(1), 61-68. https://doi.org/10.1097 /NMD.0000000000000774

Galea, S, Ettman, C, \& Vlahovs, D. (Eds.). (2019). Urban Health. Oxford University Press. https://doi.org/10.1093/oso/9780190915858.001.0001

George, M. A. (2010). A theoretical understanding of refugee trauma. Clinical Social Work Journal, 38(4), 379-387. https://doi.org/10.1007/s10615-009-0252-y 
Gouin, R. R., Cocq, K., \& McGavin, S. (2011). Feminist participatory research in a social justice organization. Action Research, 9(3), 261-281. https://doi.org/10.11 $77 / 1476750310396945$

Gray, N., Farnsworth, A., Oré de Boehm, C., \& Wolf, D. (2010). Integration of creative expression into community-based participatory research and health promotion with Native Americans. Family \& Community Health, 33(3), 186-192. https://doi.org/10. 1097/FCH.0b013e3181e4bbc6

Hyndman, J. (2011). Research summary on resettled refugee integration in Canada. United Nations High Commissioner for Refugees. https://www.refworld .org/docid/4e4b77842.html

Immigration, Refugees and Citizenship Canada. (2018). 2018 Annual report to Parliament on immigration. www.canada.ca/en/immigration-refugees-citizenship/corporate /publications-manuals/annual-report-parliament-immigration-2018/report.html

Israel, B. A., Eng, E., Schulz, A. J., \& Parker, E. A. (Eds.). (2005). Methods in community- based participatory research for health. Jossey-Bass.

Israel, B. A., Schulz, A. J., Parker, E. A., \& Becker, A. B. (1998). Review of community-based research: Assessing partnership approaches to improve public health. Annual Review of Public Health, 19(1), 173-202. https://doi.org//10. 1146/annurev.publhealth.19.1.173

Israel, B. A., Schulz, A. J., Parker, E. A., \& Becker, A. B. (2001). Community-based participatory research: Policy recommendations for promoting a partnership approach in health research. Education for Health: Change in Learning and Practice, 14(2), 182-197. https://doi.org/10.1080/13576280110051055

Jiwani, Y. (2011). Trapped in the carceral net: Race, gender, and the "war on terror". Global Media Journal: Canadian Edition, 4(2), 13-31.

Koch, S., \& Weidinger-von der Recke. B. (2009). Traumatised refugees: An integrated dance and verbal therapy approach. Arts in Psychotherapy, 36(5), 289-296. https://doi.org/10.1016/j.aip.2009.07.002

Lester, R. (2013). Back from the edge of existence: A critical anthropology of trauma. Transcultural Psychiatry, 50(5), 753-762. https://doi.org/10.1177 $/ 1363461513504520$

Mayan, M. J., \& Daum, C. H. (2016). Worth the risk? Muddled relationships in communitybased participatory research. Qualitative Health Research,26(1), 69-76. https://doi.org/10.1177/1049732315618660 
Miller, A., Hess, J. M., Bybee, D., \& Goodkind, J. R. (2018). Understanding the mental health consequences of family separation for refugees: Implications for policy and practice.American Journal of Orthopsychiatry, 88(1), 26-37. https://doi.org/10.1037/ort0000272

Minkler, M., \& Wallerstein, N. (Eds.). (2008). Community-based participatory research for health: From process to outcomes (2nd ed.). Jossey-Bass.

Moosa-Mitha, M. (2015). Situating anti-oppressive theories within critical and difference centered perspectives. In S. Strega \& L. Brown (Eds.), Research as resistance: Revisiting critical, Indigenous, and anti-oppressive approaches. (2 ${ }^{\text {nd }}$ ed., pp. 97-126). Canadian Scholars' Press.

Morgaine, K., and Capous-Desyllas, M. (2015). Anti-oppressive social work practice: Putting theory into action. SAGE Publications, Inc.

Office of the Auditor General of Canada. (2017). Report 3-Settlement services for Syrian refugees-Immigration, Refugees and Citizenship Canada. www.oagbvg.gc.ca/internet/English/parl_oag_201711_03_e_42668.html

Osman, O. T., Nasir, L., Mollica, R. F., Zoubeidi, T., Lavelle, J., \& Amawi, N. (2017). Traumainformed care survey of psychiatrists and primary care physicians in the Middle East. The Primary Care Companion for CNS Disorders, 19(5), Article 17m02157. https://doi.org/10.4088/PCC.17m02157

Palmary, I. (2018). Psychology, migration studies, and their disconnections: A review of existing research and future possibilities. South African Journal of Psychology, 48(1), 3-14. https://doi.org/10.1177/0081246317751276

Perkins, J. (2018). Settlement experiences of Syrian refugees. [Master's thesis, University of Western Ontario]. Western Graduate and Postdoctoral Studies Electronic Thesis and Dissertation Repository. https://ir.lib.uwo.ca/etd/5312

Poynting, S. (Ed.). (2015). Islamophobia and crime-Anti-Muslim demonising and racialized targeting: Guest editor's introduction. International Journal for Crime, Justice and Social Democracy, 4(3), 1-3. https://doi.org/10.5204/ijcjsd.v4i3.258

Simich, L., Beiser, M., Mwakarimba, E., \& Stewart, M. (2005). Providing social support for immigrants and refugees in Canada: Challenges and directions. Journal of Immigrant and Minority Health, 7(4), 259-268. https://doi.org/10.1007/s10903-005-5123-1

Simich, L., \& Andermann, L. (Eds.). (2014). Refuge and resilience: Promoting resilience and mental health among resettled refugees and forced migrants. Springer. https://doi.org/10.1007/978-94-007-7923-5 
Stasiulis, D. (2008). The migration-citizenship nexus. In E. F. Isin (Ed.), Recasting the social in citizenship (pp. 134-161). University of Toronto Press.

Tanasescu, A., \& Smart, A. (2011). The limits of social capital: An examination of immigrants' housing challenges in Calgary. Journal of Sociology and Social Welfare, 37(4), 97-122.

Tapp, H., Dulin, M., Steuerwald, M., \& White, L. (2013). Use of community-based participatory research in primary care to improve healthcare outcomes and disparities in care. Journal of Comparative Effectiveness Research, 2(4), 405-19. https://doi.org/10.1258/ebm.2009.009265

United Nations High Commissioner for Refugees. (2019). UNHCR Global Trends 2018. https://www.unhcr.org/statistics/unhcrstats/5d08d7ee7/unhcr-global-trends2018.html

Wallace, B., Pauly, B., Perkin, K., \& Ranfitt, M. (2015). Shifting the evaluative gaze: Community-based program evaluation in the homeless sector. Gateways: International Journal of Community Research and Engagement, 8(1), 43-58.

Wallerstein, N., \& Duran, B. (2006). Using community-based participatory research to address health disparities. Health Promotion Practice, 7(3), 1-12. https://doi.org/10.1177/1524839906289376

Wallerstein, N., \& Duran, B. (2010). Community-based participatory research contributions to intervention research: The intersection of science and practice to improve health equity. American Journal of Public Health, 100(S1), S40-S46. https://doi.org/10.2105/AJPH.2009.184036

Waters, J. (2011). Time and transnationalism: A longitudinal study of immigration, endurance and settlement in Canada. Journal of Ethnic and Migration Studies, 37(7), 1119-1135. https://doi.org/10.1080/1369183X.2011.572488

Wilson E. (2018). Community-based participatory action research. In P. Liamputtong (Ed.), Handbook of research methods in health social sciences (pp. 285-298). Springer.

Wilson, E., Kenny, A., \& Dickson-Swift, V. (2018). Ethical challenges in community-based participatory research: A scoping review. Qualitative Health Research, 28(2), 189199. https://doi.org/10.1177/1049732317690721 


\section{Biographical Note:}

Mehmoona Moosa-Mitha, PhD, is an associate professor at the School of Social Work at the University of Victoria. She is a social justice activist and scholar, working in collaboration with under-represented community organizations. Her research is situated within a broad range of decolonial practices. Correspondence concerning this article should be addressed to: Mehmoona Moosa-Mitha, University of Victoria, PO Box 1700 STN CSC, Victoria BC, V8W 2Y2. Email: mehmoona@uvic.ca

ORCID iD: iD https://orcid.org/0000-0002-9632-4610

Bruce Wallace, $\mathrm{PhD}$, is an associate professor at the School of Social Work (University of Victoria) and a scientist with the Canadian Institute for Substance Use Research in Victoria, British Columbia. He is an engaged scholar whose research focuses on poverty, homelessness, mental health and substance use. Email: barclay@uvic.ca / Twitter: @BarclayWallace

ORCID iD: ID https://orcid.org/0000-0003-0360-7302 